\title{
Formação do bibliotecário escolar: estudo de caso sobre o curso de Biblioteconomia e Ciência da Informação da UFSCar
}

\author{
Formation of the school librarian: case study of the course of Library and Information \\ Science at UFSCar
}

Tiago Fernandes Andrade Graduação em Biblioteconomia e Ciência da Informação pela Universidade Federal de São Carlos - UFSCar. E-mail: tiagobibliotecario@gmail.com

\section{Resumo}

A educação do Século XXI apresenta novas perspectivas de aprendizado para alunos, professores e familiares dentro do ambiente escolar, mudanças no ritmo de aprendizado, na busca por tornar o aluno autônomo, participativo e consciente de sua responsabilidade no processo educacional é um dos desafios da escola neste século. Preparar este aluno para ser um cidadão crítico, ativo diante dos desafios de sua vida e da comunidade a qual convive, vivencia, socializa e modifica, também é tarefa para essa 'nova escola'. Para solidificação dessa educação é preciso a utilização de diversos ambientes escolares, entre eles a biblioteca escolar que se apresenta como parte integrante do processo educacional e o trabalho em conjunto com o professor neste ambiente dará o aluno a literácia informacional, a autonomia na leitura e escrita. Ao profissional bibliotecário cabe sua atuação pedagógica dentro desse novo espaço que se modificou junto com os processos de aprendizagem e a necessidade de nova formulação das escolas de Biblioteconomia, para garantir que o processo, integração do educando e educador se concretize e o bibliotecário cumpra seu papel de informar educando. A metodologia de pesquisa do trabalho procurou conhecer a realidade das bibliotecas escolares e da grade curricular do curso de Biblioteconomia e Ciência da Informação da UFSCar, para identificar se o mesmo está preparado para atuar na área de educação básica. Os resultados apresentam que mudanças devem ser realizadas para aproximar a prática pedagógica do profissional bibliotecário.

Palavras-chave: Biblioteca escolar. Bibliotecário escolar. Formação profissional. Escolas de Biblioteconomia.

\begin{abstract}
Education of the XXI Century presents new opportunities for learning for pupils, teachers and families within the school environment, changes in the pace of learning, the search for the student become autonomous, participative and aware of its responsibility in the educational process is one of the challenges of school in this century. Prepare this student to be a critical citizen, active face of the challenges of his life and the community which lives, experiences, and socialization is also modifies task for that 'new school'. To solidify this education is necessary to use various school environments, including the school library that presents itself as an integral part of the educational process and work together with the teacher in this environment will give students the information literacy, autonomy in reading and writing. The librarian fits your educational activities within this new space that has changed along with the learning processes and the need for new formulation of the schools of librarianship in order to ensure that the process, integration of the student and educator are realized and the librarian to fulfill its role of informing student. The research methodology of the study sought to know the reality of school libraries and curriculum of the course of Library and Information Science UFSCar to identify whether it is prepared to act in the area of basic education. The results are evidence that changes should be made to approximate the pedagogical practice of the professional librarian.
\end{abstract}

Keywords: School library. School librarian. Training. Library schools. 


\section{Introdução}

Advento das novas tecnologias da informação e comunicação trouxe para a escola a responsabilidade de formar alunos agentes de mudanças na sociedade em que vivem. Este dilema apresenta, novas responsabilidades com relação a formação do aluno, ao que se chama “educação do século XXI'. Uma série de competências são necessárias segundo a National Research Council no livro Educação para a vida e trabalho, ao qual elenca três grandes vertentes de competências: cognitiva, intrapessoal e interpessoal.

O cognitivo reúne competências do aluno no que tange as estratégias de aprendizado e pensamento crítico; intrapessoal são competências que o aluno adquire para lidar com emoções e comportamento; interpessoal reúne competências em que o aluno sabe expressar pensamentos e interagir, responder a questionamentos de outras pessoas.

A educação do século XXI no ambiente escolar deve reunir fatores e ambientes diferentes para que o mesmo conheça e saiba aplicá-lo no dia a dia e não se torne uma informação de pouca relevância e mudança para o mesmo. Para atender esta demanda a escola oferta vários ambientes, espaços e profissionais para que juntos contribuam e formem os alunos diante das necessidades de sua vida e trabalho no século XXI.

O Ministério da Educação na proposição dos Parâmetros Curriculares Nacionais de Língua Portuguesa, não menciona a atuação do bibliotecário e da atuação da biblioteca como processo essencial na formação do aluno:

O papel da escola (principalmente do professor) é fundamental, tanto no que se
refere à biblioteca escolar quanto a de classe, para organização de critérios de
seleção de material impresso de qualidade e para orientação de alunos, de forma a
promover a biblioteca [...], e a constituição de atitudes de cuidado e conservação do
material disponível para consulta. Além disso, a organização do espaço físico, [...]
deve garantir que todos os alunos tenham acesso ao material disponível. Mais do que
isso, deve possibilitar ao aluno o gosto por frequentar aquele espaço, e dessa forma,
o gosto pela leitura. (BRASIL, 1997, p. 61)

Este sistema de ensino não prioriza diversos modos de aprender do aluno e incumbe ao professor o único agente modificador e construtor de conhecimento. Segundo Martucci ${ }^{1}$ (2005) o sistema educacional brasileiro é falho por propagar ações como as vistas no documento acima e também por não inferir nos projetos políticos pedagógicos escolares a atuação do profissional bibliotecário como agente transformador dentro do processo de

\footnotetext{
${ }^{1}$ Elisabeth Martucci , debatedora no livro: Biblioteca escolar brasileira em debate: da memória profissional a um fórum virtual de Neusa Dias de Macedo (organizadora)
} 
ensino-aprendizagem. Na maioria dos casos, o profissional é suprimido dos projetos do ambiente escolar.

O governo federal numa mudança do entendimento do processo educacional sancionou a Lei n. 12.244/2010 - Dispõe sobre a universalização das bibliotecas nas instituições de ensino do País, que pretende em um prazo de 10 anos que todas as escolas tenham bibliotecas e também a reserva de vagas a esses profissionais nos ambientes escolares. Essa recente legislação muda de forma radical o sistema de ensino, pois apresenta um novo ambiente para interagir e articular com as crianças, jovens e adultos presentes no processo de formação cidadã.

\section{Bibliotecas escolares no Brasil}

Estamos distantes de sermos considerados um país de leitores, segundo a pesquisa Retratos da Leitura no Brasil de 2011 realizada pelo Instituto Pró Livro, a média anual de livros por pessoa são 4, sendo a maioria didáticos e outros por indicação de leitura de professores. Os estudantes afirmam que o processo de leitura é obrigatório, ou seja, raras as situações em que os estudantes buscam a leitura como forma de distração, lazer ou aperfeiçoamento estudantil.

O Censo Escolar de 2010, apresentado por Fernandes (2012, p. 42) confirma as preocupações com a situação de leitura de nosso país. Apenas 35\% das escolas de Ensino Fundamental possuem bibliotecas, uma das causas do baixo número de leitores no país, já que o universo da leitura e seus componentes, não estão presentes no cotidiano dos estudantes e nas diversas manifestações de leitura do país.

A lei 12.444 que dispõe sobre a universalização das bibliotecas nas instituições de ensino, tem a intenção de corrigir a distorção apresentada acima e incentivar com isso, práticas prazerosas de leitura, cultura e arte com a implantação das bibliotecas escolares no país.

Há falta de políticas para construção e manutenção de bibliotecas nas instituições de ensino do país. A distribuição de livros as unidades escolares, além de não garantir o acesso aos alunos, propicia um entrave nas práticas de leitura por parte dos mesmos, já que não 
possuem espaços adequados para leitura e nem profissionais capacitados para em conjunto com os demais profissionais da escola, estimular a leitura e também escrita dos alunos.

O espaço físico das bibliotecas escolares é, na maioria das escolas, improvisado, impossibilitando assim o desenvolvimento de atividades e elaboração de produtos e serviços de informação que vão ao encontro das necessidades da comunidade escolar, no caso, professores, funcionários, alunos e pais. Esse local improvisado da biblioteca transmite a função da biblioteca escolar dada por seus administradores, à de guardiã do conhecimento e também de memória, longe da transformação social necessária nesses locais. Esse contexto da biblioteca não proporciona aos alunos a emancipação, autonomia no processo educacional brasileiro.

A segunda realidade dentro dos espaços escolares e da biblioteca escolar é quanto ao acervo, em que os livros didáticos são a maioria dentro de um universo de publicações editoriais, o que representa a falta de políticas de seleção e aquisição de livros para a composição do acervo. A inexistência da gestão profissional e falta de clareza nas políticas da biblioteca escolar, possibilita que profissionais de diversas áreas de atuação influenciem de maneira errônea a formação e composição do acervo, dificultando assim o entendimento do papel da biblioteca na unidade escolar. Além das políticas de seleção e aquisição dos livros é preciso definir a quantidade de livros para compor o acervo e segundo Campello (2004), um acervo de pequeno porte deve conter em torno de 2.500 exemplares e de grande porte a partir de 10.000 exemplares. Há neste caso, a política da Rede de Bibliotecas Escolares do SESI-SP em que para um acervo inicial há necessidade de 2 (dois) exemplares para cada aluno matriculado. As políticas implementadas na biblioteca escolar devem ser com o intuito de transformar o espaço em um local de aprendizagem, tornando-se assim, parte integrante do processo de aprendizagem e não apenas apoio ao processo educacional. Entender as nuances de funcionamento e de políticas traz a biblioteca um novo patamar de ação e mobilização dentro da escola.

A terceira realidade, ainda carente, para construção da biblioteca escolar, o profissional, que na maioria das vezes se ocupa de atividades burocráticas e administrativas, trabalha sem emoção a espera do apagar das luzes e fechamento do local. Não há emoção, empatia e dedicação pelo exercício de sua atividade no ambiente da biblioteca escolar. É necessária uma mudança comportamental para o profissional que trabalha em unidades escolares, a continuidade deste comportamento é a continuidade do processo educativo que 
hoje impera na maioria das escolas em que não se enxerga necessidade de ter o bibliotecário como parte da educação de crianças, jovens e adultos. Um espaço que deveria ser de interação é de pura monotonia e surge como aspectos determinantes a falta de diálogo em um espaço de troca de experiências do ambiente escolar.

Fragoso (2005, p. 49) apresenta a principal mudança para a biblioteca escolar:

[...] trata-se de partirmos para mudanças significativas: a biblioteca conforma-se como ambiente de fundamental importância, no interior da instituição de ensino. Ela é o coração da escola, concedendo vida à comunidade escolar, uma vez que permanece em constante sintonia com o processo pedagógico.

A transformação proposta por Fragoso exige bibliotecas abertas com profissionais qualificados trabalhando nelas e para elas, e também da integração com toda a equipe docente presente no ambiente escolar, para que a aproximação da biblioteca em seus objetivos sejam também os do projeto político pedagógico da escola e de sua ação pedagógica na construção de cidadãos que possuam consciência cívica, moral e política na sociedade. Para uma biblioteca escolar deixar de ser tratada como depósito, é necessário o estreitamento com o fazer pedagógico.

\section{Objetivos da biblioteca escolar}

Os objetivos da biblioteca escolar são vários e as maneiras de executá-los e avalia-los são obscuros quando não se tem amparos teóricos, metodológicos e práticos para que o profissional bibliotecário não fique em uma análise pessoal e subjetiva a partir de critérios elencados pelo mesmo. O conhecimento de suas ações deve perpassar pelo leque teórico para que o mesmo pratique, reproduza e tenha possibilidades de criar novas ferramentas para alcançar os desafios desejados à biblioteca escolar em sua atuação na formação dos alunos em seu período escolar.

Os objetivos da BE segundo o Manifesto da Organização das Nações Unidas para a Educação, Ciência e a Cultura (INTERNATIONAL FEDERATION OF LIBRARY ASSOCIATIONS, UNITED NATIONS EDUCATIONAL, SCIENTIFIC AND CULTURAL ORGANIZATION, 2000, p. 2) são:

a) Apoiar a todos os estudantes na aprendizagem e prática de habilidades para a avaliação e uso da informação, independente da forma, do formato ou mídia, incluindo com sensibilidade aos modos de comunicação dentro da comunidade; 
b) Favorecer o acesso a recursos locais, regionais, nacionais e globais e a oportunidade para que os estudantes exponham diferentes ideias, opiniões e experiências;

c) Organizar atividades que estimulem a sensibilidade e a consciência cultural e social;

d) Trabalhar com estudantes, professores, administradores e pais para realizar a missão da escola;

e) Proclamar a ideia de que a liberdade de expressão e o acesso à informação são essenciais à efetiva e responsável cidadania e participação na democracia;

f) Promover a leitura, recursos e serviços da Biblioteca a toda a comunidade escolar e à comunidade externa.

Observa-se que a realidade de atuação do bibliotecário é limitada ao que se tem quanto a práticas de atividades, sem critérios para avaliação da mesma, a que propósito atingiu e qual sua intensidade, além de vivenciar dificuldades na proposição de novas práticas que atendam a uma realidade de alunos cada vez mais dinâmica e que ânsia por metodologias diferenciadas que se comuniquem de forma adequada com seu ritmo de aprendizagem.

\section{Escolas de Biblioteconomia}

As escolas de Biblioteconomia formam cada vez mais profissionais técnicos e distantes da dinâmica pedagógica que são requisitos necessários para uma boa prática escolar, seja ele, qual função profissional exercer. Essa constatação é observada na atuação de bibliotecários escolares, cada vez mais percebe-se o distanciamento diante das propostas pedagógicas e assim da consciência de sua atuação no ambiente escolar. A falta de parâmetros para sua atuação e intervenção no processo pedagógico é evidente e contribui para consolidar o viés equivocado de que a biblioteca escolar não é fundamental no processo de ensinoaprendizagem.

A transformação da atuação do profissional bibliotecário alterará o ambiente escolar e ao invés de passivo as ações do processo educacional, será integrado e ativo ao processo de construção de cidadãos leitores, solidários e críticos para viverem os anseios da sociedade no século XXI. A biblioteca escolar distante deste processo educacional se torna mais uma sala de aula e não contribui para formação cidadã. 
Segundo Fragoso (2005) algumas mudanças na estrutura de cursos de Biblioteconomia e no relacionamento dos docentes são importantes:

$\checkmark$ Que as escolas de Biblioteconomia formem profissionais para atuar dinamicamente em educação;

$\checkmark$ Que as escolas que formam professores tenham em seus programas disciplinas que tratem da biblioteca como parte integrante do processo pedagógico;

$\checkmark$ Que haja projetos para bibliotecas escolares e espaços físicos adequados, e que as bibliotecas deixem de ser o eterno 'espaço provisório definitivo';

$\checkmark$ Que as bibliotecas escolares sejam gerenciadas por profissionais conscientes e integrados ao processo pedagógico;

$\checkmark$ Que as bibliotecas escolares surjam da construção coletiva, com a comunidade escolar participando de seu desenvolvimento.

A ação transformadora das bibliotecas escolares no processo educacional é o foco das ações e mudanças que devem nortear a instalação, gestão e integração a unidade escolar, projeto político pedagógico e a construção da ação pedagógica dentro das bibliotecas. $\mathrm{O}$ estímulo a práticas de leitura e escrita devem ser incentivados neste ambiente, principalmente com o desenvolvimento de projetos que envolvam alunos, crianças, adolescentes e adultos, pois os mesmos envolvem e marcam o processo educacional de cada indivíduo.

O aluno deve ter acesso a diversos tipos de textos e também ser apresentado à forma lúdica da literatura, tratar a leitura como pedagógica engessa as possibilidades de transformação que a mesma exerce sobre os indivíduos. Através do lúdico é possível aproximar diversas realidades para o aluno para que conheça e se aproprie tanto de suas responsabilidades, direitos e deveres, como para conhecimento.

Para o desenvolvimento de um ensino de qualidade a percepção de que se o professor é o papel fundamental para a escola, o bibliotecário também é:

Está comprovado que quando os bibliotecários e os professores trabalham em conjunto, os alunos atingem níveis mais elevados de literacia, de leitura, de aprendizagem; de resolução de problemas e competências no domínio das tecnologias de informação e comunicação. (INTERNATIONAL FEDERATION OF LIBRARY ASSOCIATIONS, UNITED NATIONS EDUCATIONAL, SCIENTIFIC AND CULTURAL ORGANIZATION, 2000)

\section{Aprendizagem na biblioteca escolar}

Bibl. Esc. em Rev., Ribeirão Preto, v. 2, n. 1, p. 1-19, 2013. 
O Manifesto traz nas suas primeiras linhas sobre os objetivos da biblioteca escolar a seguinte frase que reproduziremos a seguir "A biblioteca escolar é parte integrante do processo educativo." (INTERNATIONAL FEDERATION OF LIBRARY ASSOCIATIONS, UNITED NATIONS EDUCATIONAL, SCIENTIFIC AND CULTURAL ORGANIZATION, 2002, p. 2). Essa função da biblioteca escolar posiciona como uma das protagonistas do processo educacional e não de apoio ao mesmo. Para formação de leitores competentes em informação, na cultura e no uso de serviços e produtos da biblioteca escolar a IFLA/UNESCO apresentam uma série de objetivos, aos quais serão analisados individualmente para compreendermos os porquês de cada ação presente no documento.

As ações da biblioteca escolar devem ser pautadas, analisadas e observadas aos objetivos dos projetos político pedagógicos da instituição de ensino e a grade disciplinar da mesma, não devendo a biblioteca escolar agir de forma independente dessas vertentes.

Um dos objetivos da biblioteca é na criação de programas de incentivo à leitura para aperfeiçoamento da compreensão leitora dos alunos que participam do processo de ensinoaprendizagem, além de estimulá-los também através de programas para o uso adequado dos recursos e serviços da biblioteca escolar.

Ensinar o aluno a 'ler a vida' é uma das missões do bibliotecário e de outros profissionais, auxiliá-lo na diferenciação de diversas estruturas textuais, como jornais, livros, revistas, resumos, resenhas e a leitura eletrônica. Mediar os processos de leitura do aluno e as percepções que o mesmo observa no momento de suas leituras é fundamental para o amadurecimento do leitor. Extrair desse aluno posicionamentos diante da leitura que realiza sem preconceitos e prejulgamentos.

Estes programas de leitura devem ser realizados em um ambiente e metodologia prazerosa e não como castigo, punição a uma atitude indesejável do aluno. A leitura como punição possibilita um leque de desprazeres e fatores negativos aos quais no processo de leitura o aluno não será capaz de entender e compreender a beleza desta atividade na sua formação.

A criação de programas voltados ao currículo do aluno que estimulem sua prática reflexiva e de formação crítica, possibilitando a produção oral, escrita, corporal e de diversas 
maneiras e fins é necessária para a formação do futuro cidadão ciente de suas responsabilidades sociais.

Entende-se a biblioteca escolar como um organismo que vai além das necessidades informacionais de seus alunos e também é capaz da criação de programas que possibilitem diversas vivências e que interajam com professores de diversas áreas, seja com a criação de projetos voluntários para a escola, criação de grupos teatrais, de contação de histórias para que possibilite aos alunos uma infinidade de vivências e a ampliação das capacidades críticas dos mesmos, nas diversas fases da vida escolar.

Segundo Macedo (2005, p. 176) a biblioteca escolar é um "projeto institucional, em contínuo desenvolvimento, por inúmeros tipos de programas que levam o estudante ao imaginário, à sensibilidade, à diversidade cultural, ao lazer bem dirigido por meio de vivências interiores e experiências estudantis".

A biblioteca escolar é responsável, juntamente com os professores, da elaboração, desenvolvimento e avaliação de programas que buscam proporcionar aos alunos competências (conjunto de habilidades, conhecimentos e atitudes) em informação, isto inclui o saber buscar, selecionar, recuperar, usar, apropriar e produzir informação de forma responsável e consciente dentro do ambiente ao qual convivem e aprendem (escolar, familiar, social).

O bibliotecário como mediador da informação, deve estar atento a todo processo pedagógico que ocorre na escola, buscar através de fontes informais e formais, elementos que agreguem valor ao processo educativo na escola e no ambiente da biblioteca, como por exemplo, entrevista com diretores de entidades, vídeos, revistas, guias entre outros.

O treinamento dos usuários rumo ao domínio da informação é necessária, para tanto, no início do ano letivo a formação de grupos para o conhecimento dos produtos e serviços da biblioteca, formas de funcionamento, elaboração de estratégias de busca e uso dos diversos recursos presentes na unidade. Além da sinalização adequada ao espaço e organização do acervo que contemple as necessidades dos usuários da mesma. Segundo Macedo (2005) a grande função do bibliotecário é informar educando para que o mesmo através dos processos educativos seja capaz de dominar a linguagem e escrita e a partir de um processo escolar de desenvolvimento para resolução de problemas, alcance essa compreensão nas adversidades ao decorrer da vida. 
Como espaço cultural por excelência a biblioteca escolar deve incentivar e desenvolver ações culturais e artísticas dentro do ambiente para que estimulem o conhecimento, desenvolvimento e interesse dos usuários para áreas como cultura, artes e educação. A biblioteca escolar deve ser um organismo dinâmico, criativo e parceiro do aluno e da comunidade escolar como um todo.

A biblioteca deve oferecer oportunidades ao aluno, atividades em que o mesmo seja líder, coordene e direcione ações em atividades como a contação de histórias, feiras e eventos, possibilita que progrida rumo a autonomia do aluno no processo de aprendizagem, ou seja, o aluno se torna responsável e ciente de suas possibilidades de ação no processo educativo

Segundo Macedo (2005, p. 182) o ato de educar envolve várias parcerias e para a biblioteca escolar hoje, elas estão distantes, para isso a mesma incita a criação de associações para auxílio da biblioteca e evoca um dos princípios do ato educacional no século XXI:

[...] ato de formar o aluno par se tornar cidadão consciente, com liberdade intelectual e profissional, capacitado a reconstruir conhecimentos e exercitar seus direitos em ambiente democrático. Constitui propósito interiorizado por todos aqueles que têm a responsabilidade de formar crianças e jovens deste país.

Fica claro que no processo educacional não existe um só protagonista, e sim, vários atores e colaboradores em prol da construção do saber fazer, agir do aluno dentro da sociedade, começando a partir de situações escolares que simulem a vida em que o mesmo vivencia, age e modifica.

O último objetivo da biblioteca escolar segundo o documento da IFLA/UNESCO apresenta uma ampliação das capacidades de ação da biblioteca escolar, ou seja, que seu alcance seja além dos alunos matriculados no na escola e sim a comunidade próxima que necessita de seus recursos e programas para o desenvolvimento do aprendizado, a participação de processos culturais e sociais. A biblioteca escolar se tornará, a partir deste conceito, comunitária para atingir através de seus programas de leitura diversos usuários, indivíduos que buscam na biblioteca direcionamento para sua formação. 


\section{Procedimentos metodológicos}

A pesquisa e os procedimentos para conhecimento e avaliação da atual situação das bibliotecas escolares no Brasil, concomitantemente, as mudanças de objetivos que tornaram a biblioteca escolar fundamental no processo educacional e aliado a esse processo a atuação do bibliotecário e sua formação nos bancos universitários. É dentro desse contexto que a presente pesquisa se apresenta na linha de pesquisa, Educação e Cultura.

Após a escolha da temática, levantou-se fontes primárias e secundárias sobre o tema escolhido, em busca da sistematização do referencial teórico e dos objetivos e contextos encontrados na literatura e na realidade vivenciada pelos profissionais bibliotecários. As fontes de informação foram identificadas principalmente na área de Biblioteconomia e Ciência da Informação e também em programas de pós-graduação que possuem linhas de pesquisa que abordam a temática da biblioteca escolar. Além da vivência do profissional da informação em ações práticas, contextualizando o formato a ser pesquisado neste artigo.

A metodologia desta pesquisa é o estudo de caso que permite através de determinada realidade, conhecer sobre possíveis tendências e aprofundamento de princípios que se apresentam.

O estudo de caso consiste em uma investigação detalhada de uma ou mais
organizações, ou grupos dentro de uma organização, com vistas a prover uma
análise do contexto e dos processos envolvidos no fenômeno em estudo. O
fenômeno não está isolado de seu contexto (como nas pesquisas de laboratório), já
que o interesse do pesquisador é justamente essa relação entre o fenômeno e seu
contexto (HARTLEY, 1994 apud DIAS, 2000, p. 1).

A área de Ciência da Informação utiliza de forma constante este método com pesquisas em bibliotecas e sistemas de informação.

Segundo Cesar (2005):

Método do Estudo de Caso permite que seja analisada uma situação na qual não se possam fazer interferências no sentido de manipular comportamentos relevantes; neste método os dados são coletados a partir de múltiplas fontes, todas baseadas em relatos, documentos ou observações; isto significa que podem ser utilizadas inclusive evidências (dados) de natureza quantitativa que estejam catalogadas. [...] Esta é considerada uma das vantagens deste método sobre outros métodos de investigação tidos como qualitativos.

O objeto do estudo são os profissionais bibliotecários que foram observados na atuação e principalmente no processo de formação dada a estes profissionais quando estiveram nos bancos universitários quando se trata da atuação em bibliotecas escolares. 
O desenvolvimento da pesquisa ocorreu em três etapas:

$\checkmark$ Etapa 1) Pesquisa bibliográfica sobre os conceitos envolvidos no estudo e apresentados no referencial teórico, através da consulta em livros, teses, dissertações, artigos entre outras fontes de informações;

$\checkmark$ Etapa 2) Baseado no referencial teórico foi elaborado um procedimento de investigação que envolverá a apreciação de leis, manifestos, e literatura em comparação com as ementas das disciplinas do curso de Biblioteconomia e Ciência da Informação da UFSCar;

$\checkmark$ Etapa 3) Análise dos dados coletados.

\section{Resultados}

A análise das disciplinas busca compreender o leque de formação do bibliotecário formado na Universidade Federal de São Carlos e verificar se o mesmo está preparado para atuação em diversas unidades de informação e no caso específico desta pesquisa, nas bibliotecas escolares, o que envolve uma série de procedimentos técnicos e subjetivos para alcançar os objetivos da biblioteca junto ao processo educacional do aluno.

A partir da disponibilização do Nexos da UFSCar que é um sistema de desenvolvimento do processo de ensino e aprendizagem, que pretende:

[...] promover um aprimoramento sistemático da formação profissional exercida na UFSCar. Integrando planejamento, execução, avaliação e reflexão das atividades do processo, propicia aos seus principais agentes - professor e alunos de cada turma/disciplina - uma nova postura frente ao cumprimento de seus papéis, fornecendo a eles possibilidades instrumentais de ampliações significativas nos graus de percepção e de compreensão dos diversos aspectos do processo. (UNIVERSIDADE FEDERAL DE SÃO CARLOS, 2005)

O bibliotecário no mercado de trabalho tem uma reserva de mercado definida através de lei federal que garante que o mesmo é o profissional competente e habilitado para o trabalho em bibliotecas, isso inclui seu planejamento, implantação, diagnóstico e geração de produtos e serviços dentro das chamadas unidades de informação. Isso garante a absorção de grande parte dos recém-formados nas universidades para atuação em bibliotecas universitárias. 
$\mathrm{Na}$ área de Análise e Representação da Informação que busca compreender e tratar os itens documentais de forma descritiva e facilitar seus processos de recuperação, selecionamos 3 disciplinas para análise e avaliação diante da formação do bibliotecário no ambiente escolar: a primeira, Análise Documentária; segunda: Representação Descritiva de Multimeios e Recursos Eletrônicos e a terceira Representação Temática I.

A primeira disciplina tem por objetivo que o aluno ao final do processo seja capaz de identificar os diversos tipos de análise documentária, formas de representação e recuperação além de elaborar variados tipos de resumos ao público e texto a que se destinam.

A segunda tem por objetivo que o aluno conheça e aplique normas internacionais de descrição de documentos, sonoros, eletrônicos, artigos científicos e seja capaz de realizar de reconhecer o fluxo do processo de organização dos mesmos.

A terceira tem por objetivo que o aluno compreenda os processos de indexação précoordenada e da Classificação Decimal de Dewey (CDD) e seja capaz de integrar esses processos a representação bibliográfica.

Na segunda linha de concentração Disseminação da Informação selecionamos também 3 disciplinas que contemplem os propósitos, objetivos desta área para formação do aluno BCI - UFSCar: a primeira Lógica Aplicada a Recuperação da Informação; a segunda Fontes de Informação e a terceira Usos e Usuários da Informação.

A disciplina de Lógica tem por objetivo propiciar ao aluno as principais técnicas de lógica booleana para recuperação da informação, além de estimular procedimentos para o raciocínio lógico do aluno.

A segunda disciplina de Fontes de Informação visa ao final que o aluno identifique os principais recursos de informação em diferentes suportes e mecanismos de acesso; compreender as diversas formas de controle bibliográfico nacional e internacional, além de aplicar técnicas de elaboração de referencias a fontes especializadas.

A terceira disciplina da área de Disseminação da Informação é Usos e usuários da informação que pretende ao final da disciplina que o aluno seja capaz de realizar estudos de uso, usuários com intuito de identificar e criar produtos ou serviços informacionais, além de analisar os comportamentos dos usuários em suas buscas por diversos sistemas de informação e entender os fatores externos que afetam neste processo. 
A área de conhecimento Gestão de Unidades e Serviços de Informação que tem por intuito tornar o bibliotecário gestor e dentro disso seguem três disciplinas que são importantes para formação desse aluno: a primeira, Teoria Geral da Administração aplicada a Unidades de Informação; a segunda, Diagnóstico e Planejamento de Unidade de Informação e a terceira, Organização, Sistemas e Métodos para BCI.

A primeira disciplina dá ao aluno o conhecimento teórico e prático das diversas escolas da administração com intuito de aplicarem as unidades de informação, identificando necessidades, reconhecendo erros e mudando os rumos da organização diante de análises e estratégias utilizadas através das teorias administrativas.

A segunda capacita o aluno a diagnosticar e planejar unidades de informação, identificar tipos de planejamento e seus processos, estabelecer fluxos de informação e rotinas para atendimento as demandas e variadas necessidades de informação.

A terceira disciplina visa que o aluno seja capaz de analisar, e avaliar estruturas administrativas com intuito de aperfeiçoar as relações de trabalho interpessoais, homem máquina de forma a respeitar as características e necessidades físicas e psicológicas de cada indivíduo.

A última área de conhecimento é a de Tecnologias de informação e Comunicação e suas disciplinas são: Introdução a Informática para BCI; Fontes de Informação em Rede e História da Ciência e Tecnologia.

A primeira disciplina capacita o aluno nas funcionalidades do computador, hardware e software, bem como funcionalidades de editores de texto, planilhas de dados e de apresentação para que sejam capazes de elaborarem documentos, listas e planilhas dentro de seu ambiente profissional.

A segunda visa capacitar o aluno em conhecimentos teóricos e práticos da sociedade em rede, além de capacita-los para estratégias de buscas em rede e acesso a diversas bibliotecas digitais e o conteúdo dessa informação para otimização de processos.

A disciplina História da Ciência e Tecnologia visa apresentar e discutir momentos de evolução cientifica e tecnológica na sociedade dentro de uma perspectiva de evolução de suportes de informação e as consequências sociais e econômicas que essas mudanças ocasionaram nas relações de trabalho, interpessoais e cientificas. 
Diante das disciplinas do curso de biblioteconomia e Ciência da Informação da Universidade Federal de São Carlos, algumas considerações são necessárias diante da carreira profissional do bibliotecário no mercado de trabalho.

$\mathrm{Na}$ análise das áreas (Análise e Representação da Informação, Disseminação da Informação, Gestão de Unidades e Serviços de Informação, Tecnologias de informação e Comunicação) do curso BCI - UFSCar uma preocupação com as formas de recuperação, competências nas estratégias de busca em sistemas de informação, automação e padronização de procedimentos aliado a técnicas da área Biblioteconômica. Esta preocupação com os procedimentos e a capacitação dos alunos nas técnicas que serão utilizadas em sistemas informacionais são importantes para o trabalho e elaboração dos serviços nas unidades de informação e a preocupação é válida e necessária para uma formação completa do aluno.

De acordo com o projeto político pedagógico, a formação do bibliotecário da UFSCar em relação à grade curricular do projeto pedagógico de 2004, apresenta uma grande preocupação em tornar o profissional responsável, crítico e ciente de seu papel profissional como educador e transformador de realidades sociais, porém sua formação abarca de maneira sutil esta preocupação através de uma disciplina intitulada Sociedade da Informação em que se busca compreender os processos e as mudanças tecnológicas que acarretaram na exclusão social e digital. Não existe uma continuação no processo de formação do aluno para que seja capaz de compreender as transformações sociais que envolvem seu trabalho, interferindo também em sua formação e atuação como bibliotecário escolar.

Ao bibliotecário escolar além de sua formação técnica necessária para implementação e manutenção de políticas informacionais dentro da instituição escolar é fundamental sua participação no processo de construção da aprendizagem do aluno, ou seja, o bibliotecário deve atuar de forma ativa e criar mecanismos dentro de sua área de atuação para que o aluno aprenda. É evidente sua participação para transformação social, ao tornar este profissional um educador junto com outros membros da comunidade escolar. Observamos que no curso de Biblioteconomia e Ciência da Informação os alunos não são capacitados de forma básica para atuação pedagógica dentro da escola e sim como vislumbrado nas disciplinas, como um profissional técnico e capaz de elaborar planos de ação dentro da área informação, mas sem integrar ações em que se exige do profissional, questões subjetivas (integração, ações políticas da escola, formador de opinião e cultura, entre outros) que afetem seu campo de trabalho. 
O bibliotecário escolar na sua prática pedagógica deve incentivar seus usuários a leitura prazerosa e também educá-los na utilização dos recursos e usos da biblioteca escolar com a criação de programas de acordo com a gradação das séries, sejam elas de ensino fundamental, médio ou superior, em todos os níveis veem-se poucos programas de capacitação dos usuários e somente uma apresentação dos serviços o que de forma alguma capacita um indivíduo a utilizá-los.

$\mathrm{Na}$ formação do cidadão leitor é preciso ter cuidado com suas experiências sociais e cognitivas dentro de suas vivências, na criação de programas de formação do leitor pelos bibliotecários é fundamental retirar a 'categorização dos programas' assim como a definição e limitação dos espaços de leitura através de faixas etárias.

É preciso lembrar o óbvio: uma criança é um ser humano e não uma categoria abstrata e lógica. Logo, está exposta a inúmeros fatores: contextos sociais e familiares, seu próprio temperamento, acasos e acidentes, sentimentos, experiências concretas de vida, traumas, concepções culturais, entre outros fatores. (AZEVEDO, 2003, p. 80)

Nesse sentido os programas de incentivo devem-se orientar pelos contextos sociais da criança, família e escola para a formação de um adequado serviço que atinja seus objetivos aliados aos da instituição de ensino. A Biblioteconomia tem como primordial o contexto social do ambiente de atuação e como atividades meio o desenvolvimento, por exemplo, de coleções observando atentamente os objetivos educacionais e os assuntos e materiais necessários ao processo de ensino-aprendizagem. O bibliotecário em sua atuação pedagógica faria a seleção em conjunto com o professor e o saber e fazer do profissional seria referência ao processo formativo e informativo da escola.

A biblioteca deve fazer parte do projeto político pedagógico da escola com intuito de trazer para o ambiente da biblioteca ao processo educacional dos alunos, considerando a dimensão pedagógica do espaço que segundo $\operatorname{Gomez}^{2}$ (2005, p. 253)

[...] é educar e criar o hábito de ler, por meio de atos de leitura e escrita concretos que permitam a circulação da informação e a comunicação, sem esquecer da competência informacional. Desta forma, deve-se indagar na comunidade sua memória de leitura, o lugar que ocupa a biblioteca nessa leitura o que se deseja para o seu futuro.

A participação dos pais e professores neste ambiente da escola é fundamental para a construção de uma prática pedagógica do bibliotecário e para aproximar as ações com a comunidade. A biblioteca escolar e o fazer do bibliotecário devem produzir um lugar de

\footnotetext{
${ }^{2}$ Margarita Victoria Gómez, debatedora no livro: Biblioteca escolar brasileira em debate: da memória profissional a um fórum virtual de Neusa Dias de Macedo (organizadora)
} 
memória, processos de ação leitora, e a construção de novos programas e paradigmas com novas propostas de leitura, praticar a interdisciplinaridade e a inserção de múltiplos textos ao processo educacional e de leitura e escrita para resgatar a biblioteca escolar e transformá-la num ambiente em que se faz a diferença diante do processo educacional.

\section{Considerações}

A biblioteca escolar é o ambiente adequado aos alunos e comunidade escolar no intuito de estímulo a práticas de leitura, cultura, lazer e aprendizagem e o primeiro contato de alunos que estão no ensino básico com o ambiente. Em prol desse ambiente instigador devem surgir várias ações: a primeira delas é a do poder executivo em todas as suas esferas de modo a alterar a realidade das bibliotecas escolares que não se tornam parte integrante ao processo educacional do aluno, deixando uma lacuna na formação do cidadão.

O entendimento do papel da biblioteca escolar por parte dos diretores, coordenadores e professores é fundamental para a formação de parcerias rumo à educação do século XXI proposta por órgãos internacionais que visam capacitar o aluno e torná-lo competente em informação e um sujeito autônomo diante de suas necessidades informacionais, de busca, recuperação, identificação e resolução de situações problema.

A mudança dos currículos de Biblioteconomia no Brasil, especificamente da Universidade Federal de São Carlos, objeto também da presente pesquisa, se faz necessário diante da realidade da biblioteca escolar e de uma forma ampla do processo educacional em todos os níveis: básico, técnico e universitário. A alteração ou implementação de disciplinas que tratem do papel social, pedagógico do bibliotecário na área educacional é fundamental para que o mesmo seja capaz de trabalhar a área de Ciência da Informação com as demais áreas de Educação, exercitando a sonhada interdisciplinaridade no ambiente profissional bibliotecário. É clara a constatação da formação, de acordo com o currículo de hoje, de um profissional técnico e que não é capaz de identificar as necessidades e realidades sociais do ambiente em que trabalha, dificultando e reduzindo assim, sua ação para mudança e transformação social. A técnica é importante para a vivência do aluno na graduação, porém olhar aos diversos contextos educacionais ao qual a biblioteca está por excelência incluída, deve mudar a grade e o foco dos currículos na área de Biblioteconomia, para que o profissional bibliotecário, no caso deste artigo, atuar em bibliotecas escolares, ser capaz de 
fazer a diferença, entender e compreender sua dimensão social no processo de aprendizagem dos alunos e através disso ser capaz de realizar ações concretas nesse intuito. O bibliotecário escolar preparado para atuação nas unidades escolares, executa atividades culturais, de lazer e de ensino para a comunidade escolar através de programas bibliotecários e deve realizar dentro do seu contexto social e de atuação, intervenções junto ao plano docente para o estímulo a práticas de ensino que levem em consideração o lúdico no aprendizado rumo à competência informacional.

\section{Referências}

AZEVEDO, R. A didatização e a precária divisão de pessoas em faixas etárias: dois fatores no processo de (não) formação de leitores. In: Literatura e letramento: espaços, suportes e interfaces: o jogo do livro. Belo Horizonte: Autentica, 2003. p. 75-86.

BRASIL. Ministério da Educação. Parâmetros Curriculares Nacionais: Língua Portuguesa. Brasília, 2001. 38 p. Disponível em: <http://portal.mec.gov.br/seb/arquivos/pdf/livro02.pdf>. Acesso em: 06 abr. 2013.

BRASIL. Ministério da Educação. Parecer n. : CNE/CES 492/2001. Assunto: Diretrizes Curriculares para os cursos de Biblioteconomia. Brasília, 2001. 38 p. Disponível em: <http://portal.mec.gov.br/cne/arquivos/pdf/CES0492.pdf>. Acesso em: 06 abr. 2012.

BRASIL. Lei $\mathrm{n}^{\circ}$ 12.244, de 24 de maio de 2010. Dispõe sobre a universalização das bibliotecas nas instituições de ensino do País. Diário Oficial da União. Brasília, DF, n. 98, p. 3, 24 de maio de 2010. Disponível em:

$<$ http://www.in.gov.br/imprensa/visualiza/index.jsp?jornal=1\&pagina $=3 \&$ data $=25 / 05 / 2010>$. Acesso em: 05 abr. 2012.

CAMPELLO, B. Biblioteca escolar: temas para uma prática pedagógica. Belo Horizonte: Interciência, 2004.

CESAR, A. M. R. V. C. Método do estudo de caso (case studies) ou método do caso (teaching cases)?: uma análise dos dois métodos no ensino e pesquisa em administração.

REMAC Revista Eletrônica Mackenzie de Casos, São Paulo, v. 1, n. 1, p. 1, 2005. Disponível em: <http://www.mackenzie.br/ano-1_num-1.html>. Acesso em: 30 mar. 2012.

DIAS, C. Estudo de caso: ideias importantes e referências. 2000. 23 p. Disponível em: $<$ http://www.reocities.com/claudiaad/case_study.pdf>. Acesso em: 12 maio 2012.

FERNANDES, E. Bibliotecas escolares: livros tão, tão distantes das mãos dos alunos. Maio 2012. Disponível em: <http://revistaescola.abril.com.br/politicas-publicas/bibliotecasescolares-livros-tao-tao-distantes-maos-alunos-687661.shtml?page $=0>$. Acesso em: 09 maio 2012. 
FRAGOSO, M. G. Biblioteca na escola: uma relação a ser construída. Rev. ACB:

Biblioteconomia em Santa Catarina, Santa Catarina, v. 10, n. 2, p. 169-173, jan./dez. 2005. Disponível em: <http://revista.acbsc.org.br/index.php/racb/article/view/430/548>. Acesso em: 27 maio 2012.

INSTITUTO PRÓ-LIVRO. Retratos da leitura no Brasil. Brasília, 2012.

INTERNATIONAL FEDERATION OF LIBRARY ASSOCIATIONS, UNITED NATIONS EDUCATIONAL, SCIENTIFIC AND CULTURAL ORGANIZATION. Manifesto IFLA/UNESCO para biblioteca escolar. 2002. 4 p. Disponível em: $<$ http://archive.ifla.org/VII/s11/pubs/portuguese-brazil.pdf>. Acesso em: 02 abr. 2012.

MACEDO, M. (Org.). Biblioteca escolar em debate: da memória profissional a um fórum virtual. São Paulo: SENAC, 2005.

UNIVERSIDADE FEDERAL DE SÃO CARLOS. Projeto pedagógico do curso de graduação em Biblioteconomia e Ciência da Informação da UFSCar. São Carlos, 2004. 73 p. Disponível em: <http://www.prograd.ufscar.br/projetoped/projeto_bci.pdf>. Acesso em: 08 mar. 2012.

UNIVERSIDADE FEDERAL DE SÃO CARLOS. Nexos: sistema de desenvolvimentodo processo de ensino e aprendizagem da UFSCar. São Carlos, 2005. Sem paginação. Disponível em: <https://nexos.ufscar.br/nexos/apresentacao.jsp>. Acesso em: 08 mar. 2013. 